\title{
PENGARUH LINGKUNGAN KERJA, MOTIVASI, DAN KEPEMIMPINAN TERHADAP KEPUASAN KERJA KARYAWAN DIVISI ASSURANCE PWC INDONESIA DI JAKARTA
}

\author{
Jefry dan Carol Daniel Kadang \\ Program Studi Manajemen, Fakultas Ekonomi dan Bisnis \\ Universitas Tarumanagara, Jakarta \\ E-mail: jefrysso@yahoo.com
}

\begin{abstract}
This study aims to determine the effect of the relationship of work environment, motivation and leadership on the job satisfaction of employees of PwC Indonesia assurance division in Jakarta. The research sample was 100 employees. This research method uses SmartPLS and by distributing questionnaires via google form. The results of this study are that there is a positive and significant influence of work environment, motivation and leadership on the job satisfaction of employees of PwC Indonesia assurance division in Jakarta.
\end{abstract}

Keyword: Work Environment, Motivation, Leadership, Job Satisfaction.

Abstrak : Penelitian ini bertujuan untuk mengetahui apakah lingkungan kerja, motivasi dan kepemimpinan dapat mempengaruhi kepuasan kerja karyawan PwC Indonesia divisi Assurance di Jakarta. Sampel penelitian adalah sebanyak 100 pegawai. Metode penelitian ini menggunakan SmartPLS dan dengan cara menyebarkan kuesioner melalui google form. Hasil dari penelitian ini adalah terdapat pengaruh positif dan signifikan lingkungan kerja, motivasi dan kepemimpianan terhadap kepuasan kerja karyawan PwC Indonesia divisi Assurance di Jakarta.

Kata Kunci: Lingkungan Kerja, Motivasi, Kepemimpinan, Kepuasan Kerja.

\section{LATAR BELAKANG}

Dewasa ini, persaingan antar dunia usaha semakin ketat. Untuk dapat bertahan dan berkembang, suatu perusahaan harus memiliki modal, sarana dan prasarana, teknologi, serta Sumber Daya Manusia (SDM) yang baik. Sumber Daya Manusia (SDM) merupakan salah satu faktor yang berperan penting dalam jalannya suatu usaha. Setiap perusahaan dalam bidang apapun pasti membutuhkan SDM untuk melaksanakan berbagai aktivitas untuk mencapai tujuan perusahaan. Tanpa adanya SDM yang baik, produktivitas perusahaan tentu akan menurun. Oleh karena itu, setiap perusahaan harus memberikan perhatian kepada karyawannya agar karyawan dapat merasa puas bekerja di perusahaan tersebut.

Pemanfaatan SDM berkaitan erat dengan kepuasan kerja karyawan. Jika karyawan puas dengan pekerjaannya, maka performa perusahaan pun juga akan meningkat. Menurut Purnama dkk. (2019) kepuasan kerja dapat diartikan sebagai perasaan positif seseorang tentang pekerjaannya. Karyawan yang merasa puas dalam bekerja tentu ia memiliki kesenangan yang tinggi dalam melaksanakan tugasnya. Tingkat kepuasan kerja karyawan yang tinggi membuat seorang karyawan ingin bekerja lebih giat lagi, yang dapat berdampak pada kinerja perusahaan.

Salah satu faktor yang dapat mempengaruhi kepuasan kerja seorang karyawan adalah lingkungan kerja. Lingkungan kerja merupakan segala hal yang berada disekitar karyawan yang dapat mempengaruhi aktivitas karyawan dalam bekerja baik secara positif maupun negatif. Lingkungan kerja dibagi menjadi dua, yaitu lingkungan kerja fisik dan non fisik. 
Lingkungan kerja fisik meliputi suara, sirkulasi udara, tata warna, pencahayaan, dan tata letak ruangan. Sedangkan lingkungan kerja non fisik meliputi rekan kerja, pimpinan, dan bawahan. Menurut Dwijayanti dan Dewi (2015) yang termasuk dalam lingkungan kerja yang baik adalah kenyamanan dalam ruang kerja, suhu udara yang tepat, penyinaran yang cukup, tata letak ruangan yang baik, dan keamanan. Lingkungan kerja yang baik, memadai, dan kondusif membuat karyawan dapat bekerja secara efektif dan efisien sehingga hasil kerjanya dapat dikatakan optimal. Hasil penilitian yang dilakukan oleh Pawirosumarto et al. (2017) menyatakan bahwa lingkungan kerja memiliki pengaruh yang positif dan signifikan terhadap kepuasan kerja karyawan. Oleh karena itu, dapat disimpulkan bahwa lingkungan kerja berkaitan erat dengan kepuasan kerja karyawan.

Selain faktor lingkungan kerja, motivasi juga merupakan salah satu faktor yang dapat mempengaruhi kepuasan kerja karyawan. Motivasi merupakan suatu dorongan yang berasal dari luar maupun dalam diri sendiri yang membuat seseorang ingin melakukan suatu pekerjaan. Menurut Purnama dkk. (2019) Motivasi adalah suatu hal yang menjadi penggerak bagi individu untuk melakukan suatu hal demi mencapai suatu tujuan. Apabila suatu perusahaan ingin karyawannya dapat bekerja secara optimal maka perusahaan harus memberikan motivasi kepada setiap karyawan, agar karyawan tersebut memiliki keinginan untuk mencapai tujuan perusahaan. Seorang karyawan yang memiliki motivasi kerja yang tinggi, ia akan merasa lebih senang dengan pekerjaannya sehingga kepuasan kerjanya pun akan meningkat. Hasil dari penelitian yang dilakukan oleh Sathyanaravan dan Lavanya (2018) menunjukan bahwa motivasi memiliki pengaruh yang positif dan signifikan terhadap kepuasan kerja. Sehingga dapat disimpulkan bahwa motivasi memiliki kaitan yang erat dengan kepuasan kerja karyawan.

Faktor lainnya yang dapat mempengaruhi kepuasan seseorang dalam bekerja adalah faktor kepemimpinan. Kepemimpinan merupakan suatu cara yang dilakukan oleh seorang pemimpin untuk mengarahkan karyawannya demi mencapai tujuan perusahaan. Seorang pemimpin harus dapat mengarahkan karyawannya secara baik dan jelas. Menurut Adiwilaga (2018) kepemimpinan merupakan perilaku yang diterapkan oleh pemimpin untuk mempengaruhi orang lain dengan cara tertentu. Berdasarkan penelitian yang dilakukan oleh Dwijayanti dan Dewi (2015) kepemimpinan berpengaruh secara positif terhadap kepuasan kerja. Jadi dapat disimpulkan bahwa tinggi rendahnya kepuasan kerja karyawan dapat ditentukan oleh perilaku pemimpinnya.

Perasaan puas seseorang dalam bekerja dapat timbul kapan saja dan dimana saja. Karyawan yang puas akan pekerjaannya dapat menjadi faktor penting bagi jalannya suatu perusahaan. Faktor penting lainnya yang dapat membantu jalannya sebuah perusahaan yaitu laporan keuangan yang baik. Adanya laporan keuangan yang baik membuat suatu perusahaan dapat menganalisis performa keuangan perusahaan dengan jelas. Salah satu perusahaan jasa yang bergerak dalam bidang audit adalah perusahaan PwC. PricewaterhouseCoopers atau biasa disingkat dengan $\mathrm{PwC}$ memberikan pelayanan jasa berupa atestasi, perpajakan, audit, konsultasi finansial dan lainnya. $\mathrm{PwC}$ telah beroperasi di berbagai negara salah satunya di Indonesia. PwC Indonesia memiliki dua cabang yaitu di Jakarta dan Surabaya. Perusahaan PwC Indonesia merupakan perusahaan auditor terbaik dan terbesar dalam the big four auditors. Sebagai perusahaan yang bergerak di bidang jasa tentunya PwC Indonesia khususnya cabang Jakarta selalu berupaya meningkatkan kepuasan kerja karyawannya. Peningkatan kepuasan kerja karyawan tersebut bertujuan agar karyawan dapat bekerja lebih efektif dan efisien sehingga perusahaan dapat mencapai tujuan yang diharapkan.

Pada kenyataannya, untuk meningkatkan kepuasan kerja karyawan terdapat beberapa masalah yang terjadi pada perusahaan PwC Indonesia cabang Jakarta. Salah satunya yaitu, terkait dengan masalah lingkungan kerja yang kurang memadai, seperti banyaknya perbedaan pendapat antar rekan kerja yang disebabkan karena karyawan ditugaskan untuk bekerja secara 
tim sehingga sering terjadi kesalahpahaman dan perbedaan ide. Masalah lingkungan kerja yang kurang baik inilah yang dapat membuat kepuasan kerja karyawan menurun.

Selain itu, terdapat masalah lainnya terkait dengan faktor motivasi dan kepemimpinan. Adapun beberapa masalah yang terkait dengan faktor motivasi yaitu kurangnya dorongan dari pimpinan dan rekan kerja serta kurangnya dorongan dari diri sendiri untuk menyelesaikan tugas yang diberikan. Hal lain yang dirasakan oleh para karyawan terkait dengan permasalahan faktor kepemimpinan yaitu kurangnya arahan dari atasan dan kurangnya diskusi antar atasan dan bawahan. Selain itu perhatian yang diberikan oleh atasan terhadap bawahannya juga masih minim yang menyebabkan penurunan kepuasan kerja karyawan PwC Indonesia di Jakarta. Oleh karena itu, penelitian ini bertujuan untuk mengetahui pengaruh lingkungan kerja, motivasi, dan kepemimpinan terhadap kepuasan kerja karyawan divisi assurance PwC Indonesia di Jakarta.

\section{KAJIAN TEORI}

Terkait dengan konsep penelitian yang akan dilakukan ini mengenai kepuasan kerja, teori yang dapat mendukung penelitian adalah Teori Dua Faktor (Two-Factor Theory). Teori yang dikemukakan oleh Frederick Herzberg (1959), menyatakan bahwa terdapat dua faktor untuk menunjukan tingkat kepuasan seorang pegawai yaitu, faktor satisfier atau motivator (motivation factor) dan faktor dissatisfier atau pemeliharaan (hygiene factor). Faktor satisfier adalah faktor intrinsik yang akan meningkatkan kepuasan kerja, sedangkan faktor dissatisfier adalah faktor ekstrinsik untuk mencegah ketidakpuasan pegawai. Faktor satisfier mengarah pada sikap kerja yang positif karena dapat memenuhi kebutuhan aktualisasi diri.

Faktor motivator atau disebut satisfier meliputi dorongan berprestasi, pengakuan, kesempatan untuk berkembang, pekerjaan itu sendiri, tanggung jawab, dan kemajuan. Faktor kebersihan atau disebut dissatisfier meliputi kondisi lingkungan kerja, kompensasi, keamanan dan status dalam bekerja, kualiatas atasan, hubungan antar rekan kerja, serta hubungan antara atasan dan pegawai. Prinsip dari teori ini adalah meningkatkan faktor motivator untuk meningkatkan kepuasan kerja pegawai, dan meningkatkan faktor pemeliharaan untuk menurunkan ketidakpuasan kerja pegawai.

Robbins dalam Pawirosumarto (2016) menyatakan bahwa kepuasan kerja merupakan sikap seseorang yang menunjukkan perasaan atau respon emosional terhadap pekerjaannya. Jadi dapat disimpulkan bahwa kepuasan kerja merupakan perasaan seseorang yang ditunjukkan oleh sikapnya terhadap suatu pekerjaan. Lingkungan kerja menurut Afandi (2016) merupakan segala hal yang ada di sekeliling karyawan yang bisa mempengaruhi karyawan dalam melaksanakan tugasnya. Lingkungan kerja tersebut dapat berupa air conditioner, penerangan yang memadai dan sebagainya. Hidayah dan Tobing (2018) mendefinisikan bahwa motivasi adalah proses yang menjelaskan kekuatan, arah, dan kegigihan seseorang dalam upaya mencapai tujuan.

Menurut Kristianti dan Harahap (2012) kepemimpinan merupakan suatu cara yang digunakan oleh seorang pemimpin dengan maksud mengarahkan, mempengaruhi, mengontrol dan mendorong orang lain untuk mencapai suatu tujuan. Hartanto dan Turangan (2021) mengatakan bahwa, kepemimpinan merupakan sebuah proses atau cara yang digunakan oleh seorang pemimpin untuk mempengaruhi perilaku bawahan atau pegawainya. Berdasarkan definisi tersebut dapat disimpulkan bahwa kepemimpinan merupakan cara yang digunakan oleh seorang pemimimpin untuk mempengaruhi dan membina karyawannya demi tercapainya tujuan perusahaan. 
Berikut pada Gambar 2.1 di bawah ini merupakan kerangka pemikiran yang akan dijalankan pada penelitian:

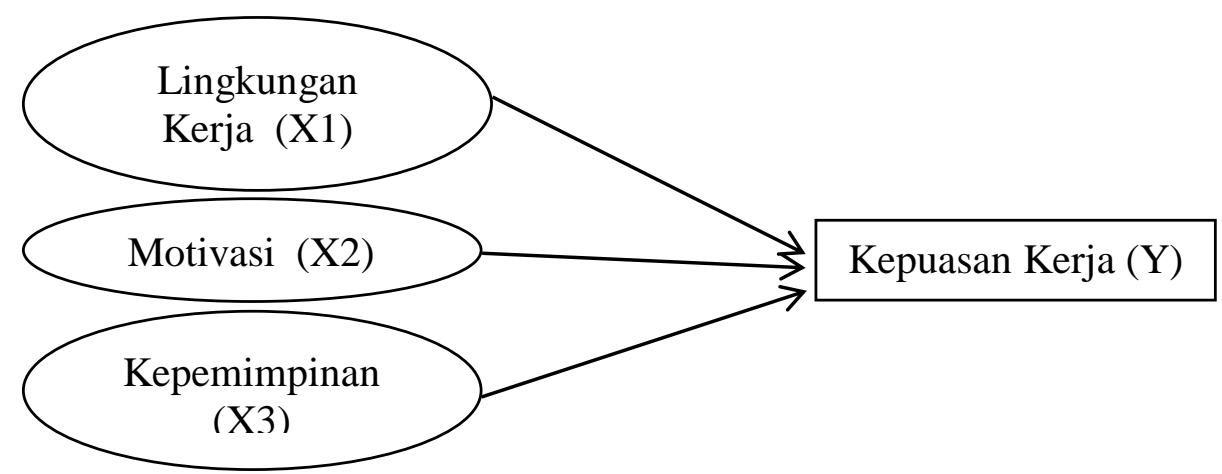

Gambar 2.1. Kerangka Pemikiran

Hipotesis yang akan dirumuskan berdasarkan Gambar 2.1 adalah sebagai berikut:

H1: Lingkungan kerja memiliki pengaruh yang positif terhadap kepuasan kerja.

H2: Motivasi memiliki pengaruh yang positif terhadap kepuasan kerja.

H3: Kepemimpinan memiliki pengaruh yang positif terhadap kepuasan kerja.

\section{METODOLOGI}

Pada penelitian ini tipe desain penelitian yang akan digunakan adalah desain penelitian deskriptif. Menurut Aritonang R., dalam Liadi dan Budiono (2019), penelitian deskriptif merupakan penelitian yang tidak ada variabel yang dimanipulasi atau disebut juga sebagai perlakuan (treatment). Penelitian ini, peneliti menggunakan cross-sectional design. Malholtra dalam Christian dan Darmawan (2019) menyatakan bahwa "desain cross-sectional adalah jenis desain penelitian yang melibatkan pengumpulan informasi dari sampel elemen populasi tertentu saja sebanyak satu kali." Jadi, konsekuensi dari desain penelitian deskriptif jenis cross sectional adalah hasil penelitian belum tentu berlaku pada masa yang akan datang, karena studi cross sectional dilaksanakan dalam jangka waktu yang relatif singkat.

Aritonang R., dalam Sunanto (2016) menyatakan bahwa "keseluruhan unsur yang menjadi subjek dalam suatu penelitian disebut populasi, sedangkan bagian dari populasi disebut sampel." Berdasarkan pernyataan tersebut, populasi merupakan seluruh unsur yang menjadi subjek dalam penelitian. Pada penelitian ini, populasi yang digunakan adalah pegawai PwC Indonesia di Jakarta divisi Assurance. Populasi pegawai perusahaan tersebut cukup besar dan tidak memungkinkan untuk meneliti keseluruhan populasi, sehingga peneliti akan mengambil sampel dari keseluruhan populasi yang ada. Dalam memilih sampel yang akan diteliti, maka peneliti menggunakan metode non-probability sampling, yaitu tiap-tiap anggota populasi tidak memiliki kesempatan yang sama untuk dipilih sebagai sampel (Aritonang dalam Chandra dan Budiono, 2019). Peneliti menggunakan metode tersebut didasarkan pada alasan adanya keterbatasan waktu dan biaya. Teknik pemilihan sampel yang digunakan pada penelitian ini adalah convenience sampling.

Mengacu pada pedoman sampel yang dikemukakan oleh Roscoe dalam Sekaran dan Bougie (2016), sampel yang tepat berkisar dari 30 sampai dengan 500. Oleh karena itu, pada penelitian ini jumlah sampel yang akan diteliti berjumlah 100 responden. 
Dalam memperoleh data maka penelitian ini akan menggunakan kuisioner sebagai cara memperoleh data dari para responden. Untuk setiap pengukuran terhadap masing-masing variabel pada penelitian ini berdasarkan acuan yang kemudian diterjemahkan kedalam bahasa Indonesia. Skala yang digunakan dalam penelitian adalah interval. Lingkungan kerja diukur berdasarkan acuan dari (Sedarmayanti, 2011). Kepemimpinan diukur berdasarkan acuan dari (Pawirosumarto et al., 2016). Kompensasi diukur berdasarkan acuan dari (Mathis dan Jackson, 2011). Kepuasan Kerja diukur berdasarkan acuan dari (Pawirosumarto et al., 2016).

Dalam penelitian ini proses analisis data akan dilakukan dengan menggunakan program partial least square (PLS). Penelitian ini dalam mengelolah data dan menganalisis data akan menggunakan software smart partial least square (PLS) versi 3.2.9. Dalam penganalsisan data dengan PLS dibagi menjadi dua pengujian yakni outer model dan inner model. Outer model merupakan pengujian yang digunakan untuk melihat hasil uji validitas dan uji relibilitas. Uji inner model yang terdiri dari uji koefisien determinan $\left(\mathrm{R}^{2}\right)$, uji effect size $\left(\mathrm{f}^{2}\right)$, uji pengukuran Q-Square $\left(\mathrm{Q}^{2}\right)$, uji kecocokan model (Gof), uji path coefficient (pengujian hipotesis), uji mediasi.

\section{HASIL ANALISIS DATA}

Penelitian ini melibatkan karyawan PwC Indonesia cabang Jakarta divisi assurance sektor Consumer Industrial Products \& Service (CIPS) sejumlah 100 responden. Dari total 100 responden, terdapat 59 responden berjenis kelamin pria, dan 41 responden berjenis kelamin wanita. Mayoritas responden berusia 20-30 tahun dan pendidikan terakhirnya adalah S1 (sarjana). Penelitian ini menggunakan skala likert dengan rentang dari satu sampai dengan lima, untuk melambangkan perasaan responden terhadap penyataan yang diajukan. Rentang tersebut memiliki keterangan bahwa satu melambangkan sangat tidak setuju dan lima melambangkan sangat setuju.

Berdasarkan hasil tanggapan responden, maka peneliti melakukan pengujian outer model untuk menguji validitas dan reliabilitas variabel penelitian ini. Pengujian validitas melalui convergent validity dapat dilihat dari nilai AVE (Average Variance Extracted) pada setiap variabel yang diuji. Selanjutnya dilakukan pengujian validitas melalui discriminant validity. Pengukuran pada discriminant validity dapat ditunjukkan melalui nilai fornell larcker dan cross loading. Pengujian lainnya yang dilakukan adalah pengujian reliabilitas yang dilihat dari nilai composite reliabilitynya. Dari seluruh pengujian validitas dan reliabilitas yang dilakukan, dapat disimpulkan bahwa semua variabel pada penelitian ini valid dan reliabel.

Hasil pengujian H1 menunjukkan bahwa variabel lingkungan kerja memiliki pengaruh yang positif dan signifikan terhadap variabel kepuasan kerja, dengan nilai nilai path coefficient sebesar 0,344 , nilai $t$-statistics sebesar 2,455 atau lebih besar dari 1,96 $(>1,96)$, dan nilai $p$ values sebesar 0,014 atau lebih kecil dari 0,05 $(<0,05)$. Hal ini mendukung penelitian yang dilakukan oleh Purnama dkk (2019) bahwa variabel lingkungan kerja dapat memengaruhi kepuasan kerja secara positif dan signifikan. Apabila lingkungan kerja yang dirasakan oleh karyawan baik, maka kepuasan kerjanya pun akan meningkat. Hal ini sesuai dengan teori dua faktor (two factor theory) yang dikemukakan oleh Herzberg (1959), bahwa faktor pemeliharaan seperti lingkungan kerja harus ditingkatkan untuk menurunkan ketidakpuasan kerja karyawan.

Hasil pengujian $\mathrm{H} 2$ menunjukkan bahwa variabel motivasi memiliki pengaruh yang positif dan signifikan terhadap variabel kepuasan kerja, dengan nilai path coefficient sebesar 0,231 , nilai $t$-statistics sebesar 2,136 atau lebih besar dari 1,96 $(>1,96)$, dan nilai $p$-values 
sebesar 0,033 atau lebih kecil dari 0,05 $(<0,05)$. Hal ini mendukung penelitian yang dilakukan oleh Qomariah (2018) bahwa variabel motivasi dapat memengaruhi kepuasan kerja secara positif dan signifikan. Apabila karyawan bisa mencapai tujuan yang ia inginkan karena adanya motivasi baik dari dalam diri maupun luar diri, maka kepuasan kerjanya akan meningkat. Hasil ini menunjukan bahwa variabel motivasi dapat memengaruhi secara positif dan signifikan variabel kepuasan kerja, sehingga $\mathrm{H} 2$ tidak ditolak.

Hipotesis ketiga yaitu $\mathrm{H} 3$, menunjukan hasil bahwa variabel kepemimimpinan dapat memengaruhi kepuasan kerja secara positif dan signifikan dengan nilai path coefficient sebesar 0,413 , nilai $t$-statistics sebesar 2,792 atau lebih besar dari 1,96 (>1,96), dan nilai $p$-values sebesar 0,005 atau lebih kecil dari 0,05 $(<0,05)$. Hal ini memiliki arti bahwa setiap perusahaan harus memiliki kepemimpinan yang baik untuk meningkatkan kepuasan kerja karyawannya. Hasil ini sejalan dengan hasil penelitian yang dilakukan oleh Pawirosumarto et al. (2016), bahwa adanya pemimpin yang mampu mengarahkan pegawainya dengan baik akan meningkatkan kepuasan kerja karyawannya. Karyawan akan merasa dihargai dan dibutuhkan. Hasil yang sama juga terdapat pada penelitian yang dilakukan oleh Palupi et al. (2017), bahwa kepemimpinan dapat memengaruhi kepuasan kerja secara signifikan, sehingga kepemimpinan merupakan hal penting yang harus diperhatikan untuk meningkatkan kepuasan kerja karyawannya.

Hasil pengujian inner model juga diperoleh berdasarkan hasil tanggapan 100 responden. Berdasarkan pengujian $\mathrm{R}^{2}, \mathrm{f}^{2}$, dan path coefficient, dapat disimpulkan bahwa variabel kepemimpinan memiliki pengaruh yang paling besar dan kuat terhadap variabel kepuasan kerja. Akan tetapi, variabel lingkungan kerja dan motivasi juga harus tetap diperhatikan untuk meningkatkan kepuasan kerja karyawan.

Tabel 1. Hasil Path Coefficient

\begin{tabular}{|c|c|c|c|}
\hline Variabel & Path Coefficient & t-statistics & $p$-values \\
\hline $\begin{array}{c}\text { Lingkungan Kerja } \rightarrow \\
\text { Kepuasan Kerja }\end{array}$ & 0,344 & 2,455 & 0,014 \\
\hline Motivasi $\rightarrow$ Kepuasan Kerja & 0,231 & 2,136 & 0,033 \\
\hline $\begin{array}{c}\text { Kepemimpinan } \rightarrow \text { Kepuasan } \\
\text { Kerja }\end{array}$ & 0,413 & 2,792 & 0,005 \\
\hline
\end{tabular}

*Sumber: Olahan data Smart-PLS versi 3.00

\section{DISKUSI}

Hasil hipotesis telah menunjukkan nilai T-statistic dan nilai $p$-values. Pada bagian ini akan dilakukan pembahasan yang berkaitan dengan hipotesis pada penelitian ini. Dengan total jumlah responden pada penelitian ini adalah 100 responden, maka berikut ini akan dilakukan pembahasan terkait dengan hasil pengujian hipotesis: 
H1. Lingkungan kerja memiliki pengaruh yang positif terhadap kepuasan kerja. Hasil pengujian $\mathrm{H} 1$ menunjukkan bahwa variabel lingkungan kerja memiliki pengaruh yang positif dan signifikan terhadap variabel kepuasan kerja, dengan nilai path coefficient sebesar 0,344, nilai $t$-statistics sebesar 2,455 atau lebih besar dari 1,96 (>1,96), dan nilai $p$-values sebesar 0,014 atau lebih kecil dari $0,05(<0,05)$. Hal ini mendukung penelitian yang dilakukan oleh Purnama dkk (2019) bahwa variabel lingkungan kerja dapat memengaruhi kepuasan kerja secara positif dan signifikan. Apabila lingkungan kerja yang dirasakan oleh karyawan baik, maka kepuasan kerjanya pun akan meningkat. Hal ini sesuai dengan teori dua faktor (two factor theory) yang dikemukakan oleh Herzberg (1959), bahwa faktor pemeliharaan seperti lingkungan kerja harus ditingkatkan untuk menurunkan ketidakpuasan kerja karyawan.

H2. Motivasi memiliki pengaruh yang positif terhadap kepuasan kerja. Hasil pengujian H2 menunjukkan bahwa variabel motivasi memiliki pengaruh yang positif dan signifikan terhadap variabel kepuasan kerja, dengan nilai path coefficient sebesar 0,231 , nilai $t$-statistics sebesar 2,136 atau lebih besar dari 1,96 (>1,96), dan nilai p-values sebesar 0,033 atau lebih kecil dari $0,05(<0,05)$. Hal ini mendukung penelitian yang dilakukan oleh Qomariah (2018) bahwa variabel motivasi dapat memengaruhi kepuasan kerja secara positif dan signifikan. Apabila karyawan bisa mencapai tujuan yang ia inginkan karena adanya motivasi baik dari dalam diri maupun luar diri, maka kepuasan kerjanya akan meningkat. Hasil ini menunjukan bahwa variabel motivasi dapat memengaruhi secara positif dan signifikan variabel kepuasan kerja, sehingga $\mathrm{H} 2$ tidak ditolak.

H3. Kepemimpinan memiliki pengaruh yang positif terhadap kepuasan kerja. Hipotesis ketiga yaitu $\mathrm{H} 3$, menunjukan hasil bahwa variabel kepemimimpinan dapat memengaruhi kepuasan kerja secara positif dan signifikan dengan nilai path coefficient sebesar 0,413 , nilai $t$ statistics sebesar 2,792 atau lebih besar dari 1,96 (>1,96), dan nilai p-values sebesar 0,005 atau lebih kecil dari $0,05(<0,05)$. Hal ini memiliki arti bahwa setiap perusahaan harus memiliki kepemimpinan yang baik untuk meningkatkan kepuasan kerja karyawannya. Hasil ini sejalan dengan hasil penelitian yang dilakukan oleh Pawirosumarto et al. (2016), bahwa adanya pemimpin yang mampu mengarahkan pegawainya dengan baik akan meningkatkan kepuasan kerja karyawannya. Karyawan akan merasa dihargai dan dibutuhkan. Hasil yang sama juga terdapat pada penelitian yang dilakukan oleh Palupi et al. (2017), bahwa kepemimpinan dapat memengaruhi kepuasan kerja secara signifikan, sehingga kepemimpinan merupakan hal penting yang harus diperhatikan untuk meningkatkan kepuasan kerja karyawannya.

\section{KESIMPULAN}

Setelah melalui pengujian dan memperoleh hasil beserta pembahasan yang telah diuraikan, maka peneliti dapat menarik kesimpulan sebagai berikut :

1. Kepemimpinan memiliki pengaruh yang positif dan signifikan terhadap kepuasan kerja.

2. Lingkungan kerja memiliki pengaruh yang positif dan signifikan terhadap kepuasan kerja.

3. Motivasi memiliki pengaruh yang positif dan signifikan terhadap kepuasan kerja.

Berdasarkan hasil penelitian yang telah dilakukan pada penelitian ini, maka terdapat beberapa saran yang kiranya dapat bermanfaat bagi perusahaan dan peneliti selanjutnya. Adapun saran yang dapat diberikan sebagai berikut:

\section{Bagi Perusahaan}

Manajer perusahan PWC Indonesia cabang Jakarta divisi assurane sektor Consumer Industrial Products \& Service (CIPS) disarankan untuk meningkatkan kepuasan kerja karyawannya, khususnya dari segi lingkungan kerja, motivasi, dan kepemimpinan. Lingkungan kerja yang 
kondusif akan memberikan rasa nyaman dan puas dalam bekerja. Hal ini dapat dilakukan dengan cara menata ulang ruang kerja agar lebih rapih dan nyaman, memberikan hiasan dalam ruang kerja agar ruang terlihat lebih hidup, memerhatikan pencahayaan ruang apakah sudah cukup atau belum, dan membina hubungan baik antar rekan kerja. Penting pula bagi manajer untuk memerhatikan motivasi karyawan. Hal ini bisa dilakukan melalui pemberian apresiasi atas kontribusi karyawan terhadap perusahaan, memberikan penghargaan atas pencapaian karyawan, memberikan semangat dan jaminan keamanan bagi karyawan. Dengan demikian, pegawai akan merasa dihargai dan puas dalam bekerja.

Peneliti juga menyarankan agar manajer perusahaan bisa memerhatikan faktor kepemimpinan. Hal ini bisa dilakukan dengan cara pelatihan bagi para pemimpin agar dapat mengarahkan, membina, dan membagikan tugas secara adil bagi para karyawan. Selain itu, pemimpin juga diharapkan dapat menjaga hubungan antara atasan dan bawahan, sehingga tercipta hubungan yang harmonis. Hubungan inilah yang dapat meningkatkan kepuasan pegawai dalam bekerja. Kinerja pegawai pun akan meningkat seiring meningkatnya kepuasan kerja pegawai.

\section{Bagi Penelitian Selanjutnya}

Untuk penelitian selanjutnya, diharapkan dapat menambah jumlah responden, mengingat jumlah karyawan di PWC Indonesia cabang Jakarta divisi assurance sektor Consumer Industrial Products \& Service (CIPS) sangat banyak. Selain itu, peneliti berharap agar penelitian selanjutnya dapat mengeksplor variabel independen lain selain lingkungan kerja, motivasi dan kepemimpinan. Variabel independen lainnya dapat berupa kompensasi, stress kerja, komunikasi, budaya organisasi, dan lainnya.

\section{DAFTAR PUSTAKA}

Adiwilaga, Rendy. 2018. Kepemimpinan Pemerintahan Indonesia (Edisi 1). Cetakan ke I. Yogyakarta: Deepublish Publisher.

Afandi, Pandi. 2016. Concept \& Indicator Human Resources Management for Management Research (Edisi 1). Cetakan ke I. Yogyakarta : Deepublish.

Duha, Timotius. 2016. Perilaku Organisasi (Edisi 1). Cetakan ke I. Yogyakarta: Deepublish Publisher.

Dwijayanti, M. N., \& Dewi, A. S. K. (2015). Pengaruh Kompensasi dan Lingkungan Kerja terhadap Kepuasan Kerja Karyawan pada Perusahaan Daerah Air Minum Tirta Mangutama Badung. E-Jurnal Manajemen, 4(12).

Hartanto, V. C., \& Turangan, J. A. (2021). Pengaruh lingkungan kerja, kepemimpinan, dan kompensasi kepuasan kerja pegawai hotel di jakarta. Jurnal Manajerial Dan Kewirausahaan, 3(2), 518-527.

Hayati, Sri. 2017. Manajemen Umum \& Sumber Daya Manusia: Bank Perkreditan Rakyat dan Lembaga Keuangan Mikro (Edisi 1). Yogyakarta: ANDI.

Hidayah, T., \& Tobing, D. S. K. (2018). The Influence Of Job Satisfaction, Motivation, And Organizational Commitment To Employee Performance.

Kristanti and Harahap, P. (2012), "Pengaruh Gaya Kepemimpinan, Komunikasi Dan Motivasi Kerja Terhadap Kinerja Karyawan (Studi Pada PT. Bank Tabungan Pensiunan Nasional Cabang Semarang)", Dinamika Manajemen USM, Vol. 1 No. 1, pp. 16-28.

Liadi, F. N., \& Budiono, H. (2019). Pengaruh dukungan pendidikan, sikap dan efikasi diri terhadap intensi kewirausahaan pada mahasiswa semester satu. Jurnal Manajerial Dan Kewirausahaan, 1(3), 447-455.

Michael Christian, T., \& Darmawan, H. (2019). Mulut ke mulut dan citra merek untuk memprediksi niat beli pada konsumen laptop asus di fakultas ekonomi universitas tarumanagara. Jurnal Manajerial Dan Kewirausahaan, 1(3), 559-568. 
Mehboob Syed Ali Abdullah, Anwar Adeel, and Hijazi Syed Tahir. 2009. Impact Of NonFinancial Reward On Employee Motivation: A Case Of Cellular Communication Service Providing Sector Of Telecom Industry Registered Under Pta In Islamabad). Cambridge Journal of The Business Review, 7(2): pp:272-277.

Moorthy, Rajeeshwaran (2014), An Empirical Study of Leadership Theory Preferences among Gen Y in Malaysia, Review of Integrative Business and Economics Research (RIBER), Vol. 3(2), 398-421.

Nursasongko, Ginanjar.S. (2012). Analisis Pengaruh Kepemimpinan, Lingkungan Kerja Dan Kompensasi Terhadap Kinerja Pegawai (Studi Pada Badan Kepegawaian Daerah Kabupaten Pemalang. Unpublished undergraduate thesis, Universitas Diponegoro, Semarang.

Noor, Juliansyah. 2016. Metodologi Penelitian: Skripsi, Tesis, Disertasi, dan Karya Ilmiah (Edisi 1). Cetakan ke VII. Jakarta: KENCANA.

Palupi, D. A. P., Cahjono, M. P., \& Satyawati, E. (2017). Effect Of Leadership On The Job Satisfaction With Organizational Commitment And Trust In Leader As Mediators. Review of Integrative Business and Economics Research, 6(4), 400.

Pawirosumarto, S., Sarjana, P. K., \& Gunawan, R. (2017). The Effect Of Work Environment, Leadership Style, And Organizational Culture Towards Job Satisfaction And Its Implication Towards Employee Performance In Parador Hotels And Resorts, Indonesia. International Journal of Law and Management.

Prasetiyo, E. J., Ratnasari, S. L., \& Hakim, L. (2020). Analisis Gaya Kepemimpinan, Komitmen Organisasional, Budaya Organisasi, Dan Lingkungan Kerja Terhadap Kepuasan Kerja Karyawan. Jurnal Dimensi, 9(2), 186-201.

Purnama, I., Nyoto, N., \& Komara, A. H. (2019). Pengaruh Gaya Kepemimpinan, Motivasi Kerja, Dan Lingkungan Kerja Terhadap Kepuasan Kerja Dan Komitmen Organisasi Karyawan Di Perguruan Tinggi Pelita Indonesia PekanbarU. Procuratio: Jurnal Ilmiah Manajemen, 7(2), 222-237.

Qomariah, N. (2018). Pengaruh Lingkungan Kerja, Motivasi dan Kompensasi Terhadap Kepuasan Kerja Karyawan. JAMSWAP, 3(2), 21-32.

Rasmi, R., Muis, M., \& Pono, M. (2020). The Impact of Compensation, Work Environment, and Commitment towards Job Satisfaction on Private High School Teachers Performance in Makassar City. Hasanuddin Journal of Applied Business and Entrepreneurship, 3(1), 82-100.

Sathyanarayan, D. K., \& Lavanya, D. B. L. (2018). Effect of Organizational Commitment, Motivation, Attitude towards Work on Job Satisfaction, Job Performance and Turnover Intentionl-VUCA Perspective. Journal of Management, 5(4).

Sekaran, U., \& Bougie, R. (2016). Research methods for business: A skill building approach. John Wiley \& Sons.

Sohail, A., Safdar, R., Saleem, S., Ansar, S., \& Azeem, M. (2014). Effect of work motivation and organizational commitment on job satisfaction:(A case of education industry in Pakistan). Global Journal of management and business research.

Sunanto, S. (2016). Pengaruh penetapan harga dan kualitas layanan terhadap kepuasan pelanggan pada apotik sunfarma tangerang selatan. inovasi, 3(2).

Tyssen, T.G. (2005), Buku Petunjuk Bagi Manajer Pemula Alih Bahasa, A.H. Pudjaatmaka (Translator), ARCAN, Jakarta.

Widiyanti, W. (2017). Motivasi Kerja terhadap Kinerja Pegawai pada Dinas Kependudukan dan Pencatatan Sipil Kota Depok. Cakrawala-Jurnal Humaniora, 17(2), 132-138. 